\title{
Theory and Practice of Time-Management in Education
}

\author{
Andrey Vladimirovich Kirillov ${ }^{1}$, Dina Kabdullinovna Tanatova ${ }^{1}$, Mikhail Vasilievich Vinichenko ${ }^{1} \&$ Sergey \\ Anatolyevich Makushkin ${ }^{1}$ \\ ${ }^{1}$ Russian State Social University, Russian Federation \\ Correspondence: Andrey Vladimirovich Kirillov, Wilhelm Pieck str., the house 4, building 1, Moscow, 129226, \\ Russian Federation. E-mail: s_makin2009@mail.ru
}

\author{
Received: February 2, 2015 Accepted: May 7, 2015 Online Published: July 30, 2015 \\ doi:10.5539/ass.v11n19p193 URL: http://dx.doi.org/10.5539/ass.v11n19p193
}

\begin{abstract}
In this article we have examined main theoretical approaches to time-management and practice of its development in education. Authors have demonstrated the need to focusing on theory and practice of time-management in Russia considering quickly-changing processes in the world and deficit of time. The various methodologies of time-management including tools, technics and methods were analyzed. Authors have showed stages of practical appliance of self-management. We have presented results of research about the role of student in time-management to improve the efficiency of educational process. The data, fixing amount of time that students spend on accomplishing different tasks, personal records, time of rest, analyzing statistical data were collecting by using timing. Analysis let us to define the structure of student's life to expose priorities, the most important, effortful and time-consuming tasks (using the tool of pair comparison). Pair comparison made it possible to compare and follow the way of changes in the structure of time management of students, based on instructive conclusions from the analysis of the first week of studies. Using polls we exposed the opinions of students about their health, dynamics of changes, negatively impacting factors etc. During research we have found the ways student waste their time, we have designed methods to overcome procrastination, we have developed ways to study using personal syllabus, video projects. Using the results of the poll we have formulated basic principles of introduction of time-management into student's life which are goal-setting, defining of priorities, timeliness, verification, balance.
\end{abstract}

Keywords: time-management, methods of using of time, self-management, tool of timekeeping, timing, technique the matrix of Eisenhower, $\mathrm{ABC}$-analysis, students time-management, sources of procrastination, traps of time, time reserves

\section{Introduction}

In the conditions of dynamic change of the world's processes the factor of time became one of the most demanded categories of the scientific analysis. Deficiency of time, its rapidity, compression, irreversibility is mentioned by the experts working in the area of policy, economy and management. In Soviet period the movie "Tale of the lost time" was very popular. The plot of the movie is rather simple: from children who didn't value the time it was stolen by angry wizards, after a series of adventures these children who turned into old men returned the time, having become children again that have their lives ahead. Unfortunately, in real life it doesn't happen - the history has no subjunctive mood and one cannot make up for lost time. Special methods of time-management are developed to operate time and to use it efficiently.

It is known that time management is a technology of increasing efficiency of usage the time for task performance. Time management presupposes conscious control over amount of time which is spent on particular types of works, increasing thus efficiency and quality of a product of activity. Theoretical bases are developed by both Western and Russian scientists, practitioners. Due to the scientific and practical importance the bases are constantly developing.

Nowadays there are a lot of approaches to efficient use of time. The most often discussed of foreign specialists in time-management is P. Druker who paid attention to complexity of management of creative process and administrative work "from above". Interesting views of time-management are presented in the works of S. Kovi (USA), L. Zayvert (Germany), K. Meller (Denmark), etc. Thanks to their development in the modern theory and 
practice there is actually a term "time management" which is widely used in scientific language including in Russia.

Management of time always was in sight of domestic scientists and practitioners in the field of the organization of work. Among them A. K. Gastev, P. M. Kerzhentsev, G. H. Popov, G. Arkhangelsky (Arkhangelskii, 2008), etc. On the basis of their works the domestic school of time-management was born, still exists and develops.

The appearance in the early seventies of D. Granin's book "This strange life" popularized a method of the biologist A. A. Lyubishchev on timing as a basis of a control system of personal time and budgeting's of expenses of time. The main idea of this method was that the effective thinking was taken as a basis of personal efficiency, and timing acted as the instrument of development of this thinking. Today the clear understanding came that time-management is the complex technology of the organization of activity focusing attention on irreversibility of time.

The problem of increase of efficiency of creative and administrative activity in the XXI century caused the necessity of concentration of attention on the theory and practice of time-management in Russia (Maloletko, 2008, pp. 20 \& 21). Certainly, we don't claim that earlier nobody paid to this aspect due attention, didn't unite the actions in space and time. At the same time, researches focused only on time-management practically weren't conducted or were focused exclusively on business. Now interpretations of opportunities are considerably extended (Kryukova \& Sokolova, 2014, pp. 51-54), use of technologies of time-management for optimization of functioning of many social institutes, including education, seems to be very perspective. So for the purpose of achievement of the most effective educational results they developed Fuzzy-approach of creation of scenarios of training (Hovakimyan et al., 2014, pp. 136-140) that in now introduces in system of electronic and distance learning. Variable of groups Work Time are used in mathematical models of scenarios of learning that demonstrate, how much time a student can spend on every kind of activity.

\section{Method}

\subsection{Bases of a Technique of Management of Time}

There are various approaches to the order, the contents and the directions of time-management - to designing of professional activity, leisure, the social environment - in the family circle, among friends, in private life, partly in health, etc. In time-management we consider various aspects of planning of human life as persons, as official, structural division, the organization in general.

In a complex the control system of time incorporates processes, tools, technicians and methods. When we plan life we can apply both individual, and group methods (Kaurova et al., 2013, pp. 1915-1917; Maloletko et al., 2015). It is useful to be guided by theories of small groups, emphasizing the social scheme of decision-making, using a technique of group decision-making and group thinking (Gwen et al., 2004, pp. 20 \& 21). It is useful to use team coaching to plan activities of students (Chulanova, 2012, pp. 2079-5505). It allows within formation of effective team to reveal and use leadership skills of members of collective, to increase their personal contribution to development of team and achievement of the objectives of team (Hackman \& Wageman, 2005, pp. 269-287). One of recognized world developers of coaching, the master of "art of transformational communication" Marilyn Atkinson, describing bases of this technology, noted: "The effort is important, but also for you personally, and in the relations with other people it is necessary to know, first of all, where exactly to apply it" (Atkinson, 2012, pp. 4 \& 8).

It is also necessary to note that it is impossible to absolutize time-management. Some researchers even consider ordered activity excessive. So Vasily Gatov, the head of RIA Novosti Media laboratory, about it has the opinion: "The daily routine is a myth, self-illusion, the formal base of metaphysical work of intellect". We beg to differ with this opinion, but to hope that time-management will solve all problems would be superficial position."

Other researcher of efficiency of use of time uses the analysis of procrastination. Leo Babauta "How to cease to postpone life for later" expressed opinion that ability to effectively solve the tasks has to be combined with procrastination, i.e. "postponement for later" in the work. Certainly, it isn't necessary to avoid postponing difficult tasks. Only the going one will master the road. At the same time we will remember a saying: "The night brings council". Procrastination (from lat. procrastinatus - procrastination, delay) can occasionally be used (but it isn't frequent, it is very important to do so in reasonable limits) as the mechanism of fight against the alarm connected with the beginning or completion of any affairs.

The management of time can assist to a number of the skills, tools and methods involved in the course of realization of a number of tasks. This range at various stages can include: statement of the purposes, distribution 
of tasks, analysis of time expenditure, monitoring, drawing up lists and arrangement of priorities, setting priorities, summing up by results, etc. processes.

\subsection{Self-management Technique}

Management of time it, first of all self-organization. For self-organization the same skills are necessary that for management of people: ability to plan, organize, motivate and control (Vinogradova et al., 2014, p. 3). The Russian researcher of experience of planning of time G. A. Arkhangelsky in one of the works in the section "the Purposes: how to approach dreams to reality" opens technology of achievement of the goal with time-management use: "Perhaps, as any other people, we, Russians, are able to dream ... To make this dreams come true, it is necessary to turn them into the goals at first ... Look at yourself as Personal Corporation, JSC Ya. This corporation has same elements of management, as at any firm, for example:

- Personal strategic planning;

- Statement of long-term goals;

- Marketing - studying of labor market;

- Personal accounts department - the account and planning of money, etc. (Arkhangelskii, 2005).

Purposeful use by the person of the evidence-based and tested work methods for the purpose of optimum use of the opportunities and time is called as self-management. Self-management pursues a main objective - realization of the opportunities in work, daily occurrence for the most optimum period. Application of self-management allows to reach the following advantages: 1 ) execution of works with smaller time expenditure and efforts; 2 ) the most effective organizations of work; 3) decrease in haste and stresses; 4) increase in satisfaction from the performed works; 5) the highest motivation of the director and workers; 6) decrease in load work; 7) increase in qualification of the head and personnel; 8) achievements of the objectives in the most optimum and effective way.

It is necessary to begin self-management with the detailed analysis of the performed works, studying of style of work and comparison of time.

About the purpose of full coverage of all kinds of activity during the first stage it is necessary to carry out inventory:

1) Analysis of types of activity and time expenditure;

2) A list of "day hindrances" breaks in work.

During the second stage we have to carry out the analysis of the inventory of time expenditure with identification strong and weaknesses. For this purpose it is necessary to carry out the analysis of the works on the following indicators performed within a week:

A - Whether there was a need of performance of work? (yes; no. "No" to enter the answer also in columns "B" and "C").

$\mathrm{B}$ - Were time expenditure designated? (yes; no).

C - Whether the time interval for work performance was consciously defined? (yes; no).

At the following stage it is necessary to count:

1) General period of work of the corresponding day (OPD);

2) Duration of works on which the director gave the answer "no" (PAS, PB, PV);

3) ratios:

a) PAS/OPD x $100 \%$;

b) $\mathrm{PB} / \mathrm{OPD} \times 100 \%$;

c) PV/OPD x $100 \%$.

In case it appears that actions of the director were optional more than for $10 \%$, it means that the director has problems with delegation of actions and definition of priorities.

If it appears that more than in $10 \%$ of cases time expenditure was exceeded, this case the head is obliged to analyze the reasons of this over expenditure.

If it comes to light that more than in $10 \%$ situations the moment of execution of work were defined spontaneously, it means that the head has problems with planning of working hours. 
At the third stage there is a processing of data from the "List of Day Hindrances".

Management in the broadest sense is a purposeful transfer of any set system in the necessary state and maintenance of the mode of its activity. In the process of self-management people carries out these actions in relation to itself as to biological system. For example, each student has to be able to plan the school hours, to set to himself tasks of development of a training material, to motivate himself on performance of these tasks and to carry out self-checking (Kirilina, 2001, pp. 1727-3749).

\subsection{Method "Timing"}

Timing is a method of studying of time expenditure by means of fixing and measurements of duration of the carried-out actions. As a result of the used equipment, we receive information on what time is spent; what is "time absorbers"; how to find reserves of time; how to develop "feeling of efficiency" and "time sense". Timing is carried out on papers, on mobile devices, records on a dictaphone, and also a remote way, online-method. About the help of the last way it is possible to conduct timing from any place where there is an Internet and by means of any device where the browser is installed (Matyash, 2013, p. 287).

During timing it is necessary to adhere to the principles, but not everyone can conduct it due to specific features. It is necessary to write down all the actions to within 5-10 minutes during at least two weeks. The most available way to conduct timing - to fix the beginning and the end of any business. In addition it is also possible to fix amount of time spent on each action and to do to them comments.

As working hours in this research it is understood - time spent for performance of educational tasks, or time of active stay on occupations. The analysis of use of working hours shows coefficient of extensive use of working hours

$\mathrm{Ke}=(\mathrm{F}-\mathrm{P}) / \mathrm{F}=1-\mathrm{R} / \mathrm{F}$, where $\mathrm{F}$ - fund of working hours, mines; $\mathrm{P}$ - the regulated and independent breaks in study, in the min. The coefficient of losses of working hours depending on students.

$K_{\Pi}=\mathrm{Pz} / \mathrm{F}$, where $\mathrm{Pz}$ - the losses of working hours depending on the student min. Coefficient of losses of working hours which are caused by the organizational and technical reasons and not depending on the student.

$K_{\Pi}=\mathrm{On} / \mathrm{F}$, where On - the losses for the organizational and technical reasons which aren't depending on students in min. Coefficient of costs of working hours of rest and personal needs of students.

Stake $=\mathrm{OL} / \mathrm{F}$, where OL - costs of time of the student of personal needs (various breaks), in min.

\subsection{Technique "Eisenhower's Matrix"}

Eisenhower's matrix is one of methods of management of time for definition of priorities of actions of day. The matrix consists of four squares which turn out when crossing axes "Important - Not very well" across and "Is urgent - Not urgently" down. To apply this matrix it is necessary to distribute the affairs according to their importance and urgency.

Important and urgent actions - what are very important and don't suffer delays. Without them everything will collapse, and to make them tomorrow - will be already late. These actions need to be carried out today, first of all - and it is obligatory.

Important, but not urgent actions are that important that urgent will become shortly. If you don't plan it to wait and to arrange yourself unnecessary "race", pay the closest attention to these affairs.

Affairs not important, but urgent. As a rule, in actions not approaching you to the purpose get here.

Neither important, nor urgent affairs are not necessary category of affairs. They aren't important, they aren't urgent, but they want to be done. These are your "devourers" of time - reading glossy magazines, computer games, viewing of TV programs, travel on the Internet, shopping.

The accelerated analysis by Eisenhower's principle is auxiliary in cases when it is necessary to make urgently the decision on priority of performance of tasks. Priorities are established by such criteria as urgency and importance of a task.

\subsection{Pareto's Method}

The sequence of performance of actions can be defined by Pareto principle which says that $80 \%$ of tasks can be solved for $20 \%$ of the spent time; for the remained $20 \%$ of tasks $80 \%$ of the spent time (Law 80/20) are spent.

The universal principle offered by Ryszard Koch referring to the private regularity revealed in 1897 by the economist and the sociologist Vilfredo Pareto. Results of research of Koch are reflected in the book "the Principle 20/80: secrets of achievement of big results at expense of smaller efforts". 
The most important consequences of the law of Pareto

- It is a little significant factors, and factors trivial a set - only single actions lead to important results.

- The most part of efforts doesn't yield desirable result.

- That we see isn't always true - always there are hidden factors.

- That we want to receive, as a rule, differs from that we receive as a result.

- It is usually too difficult to understand that occurs, and often in it there is no need.

- The majority of successful events are connected with action of a small number of high-performance forces; the majority of troubles are connected with action of a small number of high-destructive forces.

- The most part of actions, group or individual, bears for itself waste of time. They don't yield anything for achievement desirable result.

The key to successful management of time is that it is necessary to focus efforts on the end results, but not on the process of work. Concentrate and believe that is accurately established in principle to Pareto, or the law 80/20. In lives, the account there cannot always be $80 / 20$, but this main sample of a ratio in work with significant result.

Concentrate and believe that is accurately established in principle to Pareto, or the law 80/20. In lives, the account there cannot always be $80 / 20$, but this main sample of a ratio in work with significant result.

\subsection{Method of "Tomato" and ABC Analysis}

$\mathrm{ABC}$ analysis is the method allowing classifying tasks of degree of their importance. This analysis is one of methods of rationalization and can be applied during study. The technique allows to define the analysis purpose (why, this analysis is necessary?); to define actions following the results of the analysis (that we will do with results?); to choose object of the analysis (that we will analyze?) and analysis parameter (on what sign we will analyze?); to make a rating of objects on decrease; to calculate a parameter share from the total amount of parameters with an accumulative result; to allocate groups A, B and C and to appropriate values of groups to the chosen objects.

The technique identification of priorities by means of the analysis of $\mathrm{ABC}$ is based that parts as a percentage of the most important and least important issues in the sum remain untouched. All tasks are subdivided into three categories according to their importance. The analysis of $\mathrm{ABC}$ is based on three regularities: the most important issues make $15 \%$ of their general quantity in which the student is engaged. The contribution of these tasks for achievement of the purpose makes about $65 \%$; important tasks make $20 \%$ of their general quantity, the importance them for achievement of the purpose makes about $20 \%$; less important tasks make $65 \%$ of their general quantity, and their importance makes $15 \%$.

\subsection{Technique of Research on a Subject: "Time-management of Students of Higher Education Institution"}

During training of heads of various levels by the major the moments in their formation the formation period at them the main professional knowledge, skills, competences is when training in higher education institution (Kryukova et al., 2014). Therefore within this research the problem of identification of a role and a place of student's time-management in learning efficiency increase was solved. The solution of this problem will become the first step in further identification of ways of increase of efficiency of heads due to competent use of opportunities of time-management.

After detailed studying of the available techniques of time-management the main stages of carrying out research were defined:

1. Drawing up chart of use of time. In case you want to operate time, have to understand accurately how your day shares on educational and daily affairs. Control of personal time is necessary to help you to understand, what is the time you spend for private life, and how many - for study.

2. Optimization of distribution of time, specification of time allocated for study (classroom occupations at university, independent work). Efficiency of process assumes that time isn't spent for aimless affairs. In this regard it is necessary to reveal, lives, what of spheres, lead to a waste of time.

3. Identification of "time traps" and definition of ways of their overcoming. Sources of a waste of time prevent to carry out the best plans and intentions. It is necessary to protect time, to be able to give refusal to various foreign affairs, circumstances, requirements or people.

4. Rational planning of school hours and realization of ways of overcoming of "time traps". Skillful management of time stimulates the person to implement the plan of measures most effectively and expediently. Thus 
development of the plan doesn't take away a lot of time. For example, the schedule for a week can be made less than for an hour.

By means of timing (timing) data were collected and time volume spent by students for performance of various type of works, personal records, rest was studied, statistical data (mathematical statistics) were processed. The analysis allowed determining structure of activity of the student for identification in it of priorities, the most important, labor-consuming and by time of expensive affairs (a method of paired comparisons). The comparative analysis gave the chance to compare and analyze nature of changes in structure of time-management of the students made on the basis of instructive conclusions of the analysis of the first educational week. By means of questioning the opinion of students about condition of their health, dynamics of changes, negatively influencing factors, etc. came to light.

\section{Results}

\subsection{Drawing Up Chart of Use of Time}

The educational group of a third year (28 people) was involved in research of influence of time-management on learning efficiency. Coverage of groups was assumed $100 \%$. However the insignificant part of students (3-5\%) for various reasons didn't get to research group (an illness, participation in competitions, other objective reasons). The project manager, the faculty acted as coaches (Chulanova, 2010, pp. 39-46) who promoted search of internal resources by students.

Research was conducted during a semester. The analysis of results of the previous semester showed that $20 \%$ of students handed over session perfectly, $40 \%$ - are good and $40 \%$ - are satisfactory. For identification strong and weaknesses of planning of time the technology of timing (timing) was used. This procedure allowed to find out, on what valuable minutes and hours are spent.

From educational group two subgroups of students on the basis of removal of the place of residence from university, buildings, educational audiences in which classes are given in various subject matters were allocated. One of tasks, put detection of nature of use by the students living rather near university, that surplus of time which appears from a difference of the time expenditure received at promotion of students from the house on occupations.

The first subgroup is the students living at a great distance from university (a share of time for the road of $10-20 \%$ from educational week - Figure 1) and the second group - the students living near university (a share of time for the road to educational cases of 2-10\% from educational week - Figure 2).

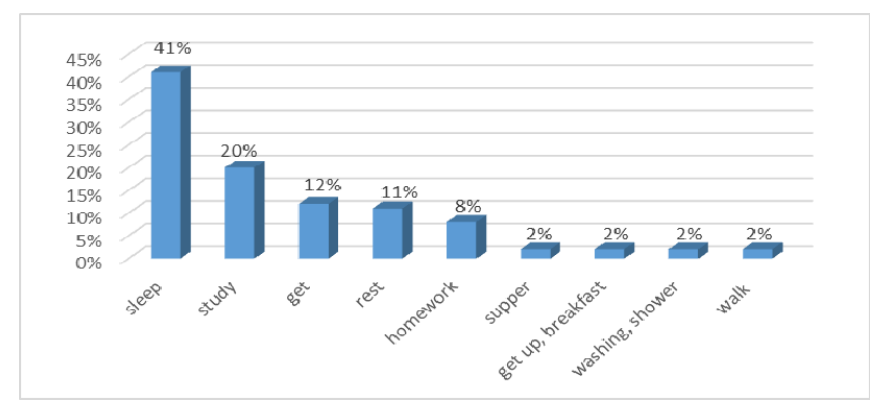

Figure 1. Distribution of time students during the 1st educational week living far from higher education institution

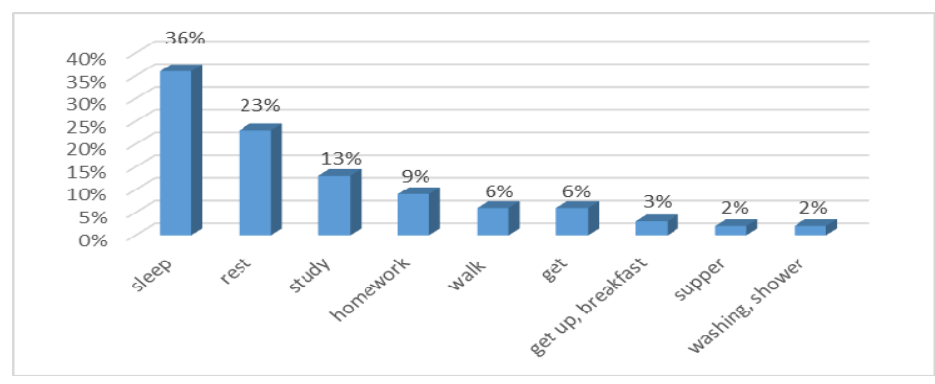

Figure 2. Distribution of time students during the 1st educational week living near higher education institution 
The analysis of results of timing of the first educational week of subgroup of the trainees living far from university showed that most of students allow a lot of time for a dream. During discussion with them the main indicators of distribution of time during the 1st educational week on tasks, it was succeeded to establish that for them it's not very important to allow about $40 \%$ of time of the studied week for a dream. The relation at the right time was irrational that was confirmed during discussion of their activity. It was characteristic as for students of the first subgroup ( $41 \%$ of time for a dream), and for students of the second subgroup (36\%). Allocation of smaller time for a dream by students of the second group is explained by that, without spending a lot of time for moving, students are tired less, have more opportunities to have a rest and without dream. The exception was made by students who were engaged according to the individual plan. At them on a dream $27 \%$ of time left. It should be noted that it was $3 \%$ of educational group.

At students of the second subgroup who lived rather near higher education institution, the structure of timing and quantitative indices differed (Figure 2) a little. The road took $6 \%$ of time from them; however the dream also prevailed over all other affairs, and significantly and insufficiently reasonably. Thus during the 1st educational week at the second subgroup, in higher education institution essential deviations from the first subgroup had time for occupations, and made only 13\%, and homework (independent work) - 9\%. A lot of time within preparation in the direction human resource management was allowed to rest $(23 \%)$ where reading books, the Internet, exercises (sport), cleaning of the room and cooking were included. Unlike the students who are far living from higher education institution, trainees of this subgroup had opportunity (mainly, girls) to be prepared for an exit from the house (appearance, clothes, a make-up, etc.) that also entered rest.

\subsection{Optimization of Time Distribution}

By results of the first week individual interview, and also discussion as a part of educational group was conducted. During conversation with students teachers used coaching elements; they drew attention of trainees to health issues. As a result of the done work, the analysis of data of the first week, students independently changed the plan of activity per day, week and in the long term, to a semester. After that, in a month, students repeatedly carried out timing of the educational (working) week.

The desire to look for time reserves in such expensive indicators as a dream became important feature of students of the first group. Time for a dream at the students living far from higher education institution was reduced by $3 \%$ (Figure 3). Despite rather verified schedule of promotion in university, students could optimize also it, having reduced time for the road for $3 \%$. More attention began to be paid to questions of study (in the sum with homework) for $2 \%$, health, personal hygiene (rest, walk, a shower) for $2 \%$. Thus, time for a lunch entered study as students ate food on changes between occupations. Time for a dinner increased by $1 \%$. It was connected with that during a dinner students sought to communicate more with the relatives and acquaintances, discussing, including, questions of optimization of the time-management.

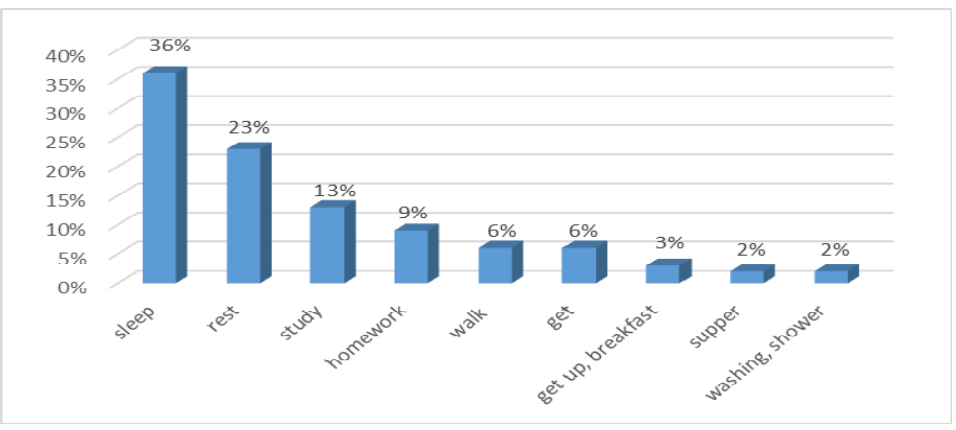

Figure 3. Distribution of time by students during the 2nd educational week living far from higher education institution

Students reasonably began to find less time for a dream for $4 \%$, having finished its duration honor up to the optimum size, and to rest for $7 \%$. Communication was reduced by personal subjects. Thus time for study for $5 \%$ and homework for $7 \%$ was increased. Part of students within these indicators began to give more attention to learning of foreign language (generally English), some signed up for English language courses. As well as in the first subgroup, within rest students began to pay more attention to health, physical development. The expense of time for reading books and the Internet remained the same, but emphasis was placed more on those e-book 
readers and the sites which are devoted to professional knowledge. The students who were engaged according to the individual plan tried to reduce time for the road, having increased an academic load.

In general, in the educational group attracted to carrying out experiment on identification of influence of time-management on learning efficiency during a semester there was an optimization of use of time for activity to focusing of attention to study. Change and in quality, and depth of the gained knowledge resulted. All this was reflected in results of regular session. The group increased progress: $40 \%$ of students handed over session perfectly well, $45 \%$ - for well and $15 \%$ - on well.

The students of the second subgroup living near higher education institution also had changes to the best (Figure 4).

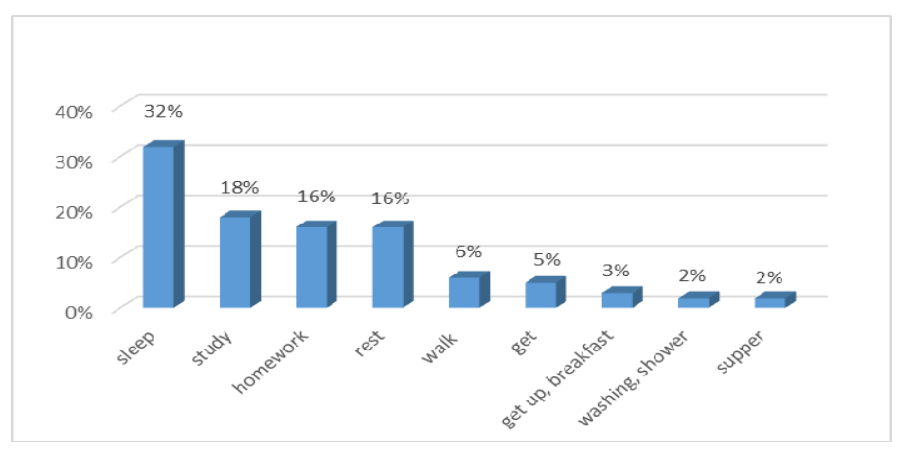

Figure 4. Distribution of time students during the 2nd educational week living near higher education institution

\subsection{The "Time Traps" and How to Overcome It}

During research sources of a waste of time were opened. For both groups the dream became the main and unreasonable factor of loss of time. The excessive amount of time was spent for a dream, and, eventually, was reflected in study, and for health. For the first subgroup on the second place there was a problem of a waste of time on the road to university. It had, mainly, objective character. However and in this question ways of optimization of this indicator, reduction of time were looked for. Both groups suffered from attempts of transferring of terms of performance of objectives. Preparation for occupations at university also had certain "absorbers" of time. For both subgroups phone calls of friends and relatives, unforeseen meetings, and also switching on minor interests during the work on the Internet became the vital issue absorbing a time resource. Shift of priorities when performing homework reduced efficiency of preparation. The analysis of structure of rest of the first group showed that unforeseen circumstances, absence of plans for rest, sudden meetings, change of the schedule of transport, etc. became important "absorbers" of time. At the students living near university, a lot of time left on unforeseen communication, telephone negotiations, Internet communication and in certain cases shopping. "Blockages" on some subjects were also characteristic. Students didn't manage to do the received tasks.

Research allowed defining ways of overcoming "time traps". Students looked for reduction of time for the road in the optimum schedule of transport to university. There was a search of reduction of influence of such "absorber" of time as telephone calls/messages on occupations, derivation on the Internet, talk on abstract subjects. The structure of knowledge acquisition on occupations was studied. Reserves were found in technology of approach to knowledge acquisition through individual development plans, video projects (Zeveke, 2013, p. 44).

Thus the positive effect of communication on a study subject - additional and operational information for preparation for seminars, offsets and examinations was found. Part of the assigned tasks students "delegated" to the companions, invited to participate them in preparation for seminars collectively (Skorokhodova, 2010, pp. 242-245). Constantly attempts in time to carry out the tasks set by teachers, not to allow incomplete affairs became. Process of training in higher education institution began to be planned by students independently, with a support for lesson schedule. Thus students sought to minimize number of unforeseen meetings, switched-off phones on occupations, by preparation for seminars. Also communication time on social networks decreased. The requirement of the faculty for maintenance of an order on a desktop during occupations, the ambiance when performing independent work was transferred in house. 
Work according to the plan - the most important skill of management of time. Research showed that only careful planning answering questions: what to do when to do and with use of that to do, allows to perform necessary work qualitatively. According to Kirill and Mefodiy's encyclopedia, the plan is the in advance planned order, sequence of implementation of any program, performance of work, carrying out actions. According to the list of concepts developed in the Russian Academy of Sciences, the plan is a directive definition of the list and terms of actions, proceeding from definite purposes, resources allocated for achievement of these purposes, scientifically based standards of an expenditure of resources. As a matter of fact, if decision-making is a thought process, planning is text (tabular) or (and) graphic reflection of its results on paper (the computer file, a board, other data carrier). Still A. Fayol considered management of people as an integral part of a social and natural organism (Kirillov, 2013, p. 236). Planning of school hours gives the chance evenly to distribute efforts of the theoretical knowledge which is trained between assimilation and acquisition of practical production skills (Dolgorukova, 2014, p. 165).

Experience of time-management which student's musicians shared was useful. Of course, "it is necessary to consider specifics of music as special type of spiritual creativity of the person" (Shcherbakova, 2012, p. 34), but thus comprehension of the musical composition demands the accurate plan, very exact distribution of time. As young musicians explained, the inspiration comes only if all "draft" work is qualitatively performed. And the more accurately it is planned, the quicker it is possible to reach desirable result.

As a result of experiment most of students began to consider and distribute every evening the opportunities the next days, to prepare the list of tasks, to place priorities in their performance. Before day, they looked through the list, kept it around, and at the end of day counted number of the achievements. Many ordered the plans by means of a method of "Alps" which covers five stages: streamlining of tasks, an assessment of duration of actions, reservation of time (in the ratio 60:40), decision-making on priorities and control of the account executed.

\section{Discussion}

On the relation to time-management, people can conditionally be divided into some groups. The first considers that time-management is necessary for achievement of success, the second - that is an unnecessary invention, everything becomes in itself, "go down stream". The third category would also like to change something in the life, but there is no concentration, persistence. For student's time-management, it became clear by results of research, all three points of view take place.

During identification of a role and a place of student's time-management in increase of learning efficiency it was succeeded to establish that the modern technology of management of time of students is poorly mastered and is insufficiently actively used. It was established that the vast majority of students (97-99\%) have no experience and even concept as it is correct to set the object to plan the life, activity, study in higher education institution. Thus $92-98 \%$ of students even under pressure of teachers with a big reluctance planned the life. Attempts in planning of the actions with a support on time-management showed very weak results. The available time resource during training in the University is used irrationally.

After the analysis of the timing, most of students reconsidered the views of expediency of planning of own time, introduced amendments in the organization of the life, and first of all, in training process. The role and a place of time-management in achievement of learning efficiency became considerable. During development of model of personal time-management students faced problems, as in a formulation of the accurate purpose, and technology of its achievement. In the beginning only the formalized actions set by higher education institution were, as a rule, reflected in plans. On the end of experiment, more than $70 \%$ of students really began to apply consciously and purposefully time-management in the life.

As the fundamental principles of introduction of time-management in student's life the following was allocated:

- Goal-setting. The initial principle of management in general and managements of time, in particular, is the goal-setting, i.e. a purpose formulation. The purpose is a first step in management. Under the purpose in management, usually understand some ideal, in advance set result which should be reached. This multidimensional and many-sided idea of the future. If not to define the purpose for day (week, month), exclusively aimless pastime will be observed. Definite purposes give the chance to exercise purposeful control over management of our time, and thus, promote achievement of success. The main requirements when determining the purposes are: their orientation in time, consistency, concreteness, measurability, approachability and at the same time greatest possible complexity. 
- Priority - ranging of the purposes and tasks of their importance. Effective management of time is based on the list of the main priorities. It is impossible to spray the efforts. The available time should be distributed depending on importance and the importance of work.

- Timeliness (one doesn't sharpen the axes after the time they are needed). It is very important to appoint the concrete term of performance of each work. The task which is accurately not localized on time usually isn't carried out at all. The appointed terms have to be real for effective implementation of work. The defined completion date of work is the obligation which gives to the carried-out task real outlines. Besides, it is impossible to forget that not only failure, but also untimely performance of business reduces a self-assessment, negatively influences a psychological state of the person. At successful and timely end of people feels pleasure. Main objective of the student: will learn to study (Zeveke, 2012, p. 127). And it is possible to make it only if you derive pleasure from training process.

- Verification (ability to check) - a way of confirmation of that works are conducted according to the set requirements. The success of realization of this principle in many respects is defined by the clearness of the chosen indicators of efficiency and criteria of their assessment.

- Balance (there are no ideal decisions) assumes the account strong and weaknesses of the made decisions, and also their next and long-term consequences. Proceeding from this principle, it is necessary to support optimum balance, between all spheres of life, applying effective management of time.

Introduction of time-management in student's life was followed by objective and subjective difficulties. Students, quite often, aspiring to the purpose, didn't pay attention to fine details, and as a result implementation of the conceived departed on a distance shot. It is known that trifles in important issues don't happen. Research showed also importance of allocation of a reserve of time for unforeseen circumstances. It is important to learn to perceive study adequately and reasonably. Fight against "absorbers" of time had quite often fragmentary character, but allowed to increase efficiency of time-management of students. Attempts to systematize the time, the everyday life worked well not for all students.

Positive effect of the prolonged action of pedagogical experiment was that most of students after the end of experiment continued control of the time, the content of educational, labor and private life, constantly noting the achievements in increase of efficiency of use of time. Session showed that at $90 \%$ of the students participating in experiment progress raised: $35 \%$ of students perfectly handed over session, $55 \%$ - are good, and only $10 \%$ remained on satisfactory positions.

One of the main conclusions drawn by students - continuous carrying out timing for continuous optimization of the life, improvement of the personal time-management, provides high-quality development of future profession.

\section{Conclusion}

A life rhythm in which we live, it is hardly possible to call measured and quiet. Daily planning a set of affairs, something is constant we aren't in time, we postpone to other time, or we postpone for some days. The emotional pressure from a constant lack of time reduces labor productivity, leads to emotional "burning out", fast apathy and fatigue. For this reason time it is possible and it is necessary to operate, using modern methods of management of time. More precisely, it is necessary to operate competently by it to derive the maximum benefit from time which is available at our disposal.

Results of research allow drawing a number of conclusions concerning a role and a place of student's time-management in their preparation. Despite aspiration to get an education in the management sphere, overwhelming number of students independently don't use the resources put in technology time-management independently (Kozhaev, 2012, p. 168). During experiment the attention of students to how to make the life, study of more organized was drawn. Students sought to reveal the problem zones in the time-management, to define ways of its optimization.

In change of student's time-management reduction of time for a dream became characteristic, more attention began to be paid to questions of physical culture, health, cultural education. Reading literature, viewing of movies, the Internet was implemented on the way to university; time for performance of more important issues in stationary conditions thereby was found. There was an aspiration to save every minute that isn't always characteristic at young age. The route in university, work and other objects for saving of time was in more detail studied. Students became more serious to treat not simply study in HIGHER EDUCATION INSTITUTION, but also vocational training in a broader sense. Besides that time for study and performance of homework increased, time for additional learning of foreign language (courses) also began to be allocated. In individual plans of 
students there were new tasks - visit of fairs of vacancies, specialized exhibitions on human resource management, management, training on courses on innovative technologies of HR management, etc.

In general, studying and introduction of student's time-management in process of preparation of administrative personnel allows to increase learning efficiency in higher education institution, will facilitate career development of future directors.

\section{References}

Arkhangelskii, G. A. (2005). Time Drive: How to have time to live and work. Moscow, NY: Mann, Ivanov and Ferber.

Arkhangelskii, G. A. (2008). Corporate Time Management. Encyclopedia solutions. Moscow, NY: Alpina Digital.

Atkinson, M. (2012). Mastery of life. The internal dynamics of development. Moscow, NY: Alpina Publisher.

Chulanova, O. L. (2010). Formation, development and coaching emotional competence in personnel management: Monograph. Surgut, NY: Hyphen.

Chulanova, O. L. (2012). Coaching emotional competence of management personnel of the organization. Social Sciences, 1(286-294), 2079-5505.

Dolgorukova, I. V. (2014). Organization of constructive interaction of the higher education system and modern organizations in the training of specialists. Social policy and sociology, 4(163-172), 2071-3665.

Gwen, M. W., Andrea, B. H., Paul, B. P., Randy, Y. H., Deborah, G. A., Randall, S. P., .., Kay, Y. (2004). The functional perspective as a lens for understanding groups. Small group research, 35(1), 17-43. http://dx.doi. org/10.1177/1046496403259459

Hackman, R., \& Wageman, R. (2005). A theory of team coaching. Academy of Management Review, 30(2), 269-287. http://dx.doi.org/10.5465/AMR.2005.16387885

Hovakimyan, A. S., Sargsyan, S. G., \& Ziroyan, M. A. (2014). Method for E-Learning Scenarios Creating. Publications International Scientific Conference 24-29 March (pp. 136-140). Part II.

Kaurova, O., Maloletko, A., \& Yumanova, O. (2013). Cross-country Comparison of Statistical Indicators. Life Sci. J., 10(4), 1915-1917.

Kirilina, T. Y. (2001). The features of socialization of students in modern Russia. Bulletin of Moscow state University of forest and Forest Bulletin, 3(24-29), 1727-3749.

Kirillov, N. P. (2013). Theoretical background the institutionalization of socio-environmental management. Social policy and sociology, 2-1(228-251), 2071-3665.

Kozhaev, Y. P. (2012). Some aspects of social mobility students: training and technical development. Materials Afanasievsky readings, 1(10), 163-172.

Kryukova, E. M., \& Sokolova, A. P. (2014). Assessment of Efficiency of the Hotel Management by a Russian Company. World Applied Sciences Journal, 30(Management, Economics, Technology \& Tourism), 51-54.

Kryukova, E. M., Makeeva, D. R., \& Konovalova, E. E. (2014). Tourism as Preferred Direction in the Strategy of Substitution of Industry Branches in Mono-Territories of Russian Federation. World Applied Sciences Journal, 30(Management, Economics, Technology \& Tourism), 176-178.

Maloletko, A. N. (2008). The national interests of the Russian Federation in the field of education. Moscow, NY: Russian state university of tourism and service.

Maloletko, A. N., Kaurova, O. V., Kryukova, E. M., Pochinok, N. B., \& Gladko, E. A. (2015). Analysis of key indicators of tourism industry in Russia. Modern Applied Science, 9(3), 25-33.

Matyash, S. A. (2013). Informational security of the person in the modernization of Russian society. Social policy and sociology, 2-1(285-296), 2071-3665.

Shcherbakova, A. I. (2012). Cultural perspective on the problem of understanding of music and music education. FEN-SCIENCE, 14(34-36), 2224-1744.

Skorokhodova, E. Yu. (2010). Some Methods of Independent Study Management. Modern Models of Languages and Cultural Studies as the Part of Education Quality Management. The materials of the IV academic conference, 20, 242-245. Moscow: RSSU.

Vinogradova, M. V., Kryukova, E. M., Kulyamina, O. S., Vapnyarskaya, O. I., \& Sokolova, A. P. (2014). 
Approaches to the study of the status and trends of drug abuse, rehabilitation and reintegration of drug users. Biosciences Biotechnology Research Asia, 11(3), 1505-1514. http://dx.doi.org/10.13005/bbra/1545

Zeveke, O. Y. (2012). The Study of professionalism in social management. Materials Afanasievsky readings, l(10), 123-131.

Zeveke, O. Y. (2013). Some aspects of the psychological perception of students of computer technologies in teaching. A educational-methodical collection of the Department of social management and tourism "Problems of training and retraining of specialists in the field of hospitality and tourism", 41-45. Moscow, CA: Russian State Social University.

\section{Copyrights}

Copyright for this article is retained by the author(s), with first publication rights granted to the journal.

This is an open-access article distributed under the terms and conditions of the Creative Commons Attribution license (http://creativecommons.org/licenses/by/3.0/). 